\section{Commentary: Connecting the dots: Coronary artery development as a combination of vasculogenesis and angiogenesis}

\author{
Lillian Kang, MD, ${ }^{\mathrm{a}, \mathrm{b}}$ Nicholas D. Andersen, MD, ${ }^{\mathrm{a}, \mathrm{b}, \mathrm{c}}$ \\ and Joseph W. Turek, MD, PhD, MBA ${ }^{\mathrm{a}, \mathrm{b}, \mathrm{c}}$
}

Unlike the well-characterized development of systemic arteries, the complex morphogenesis of coronary arteries remains a field of active investigation. What is clear is that coronary arteries do not develop in a straightforward manner via simple angiogenesis or vasculogenesis alone. The existing body of literature consists of studies that address narrow aspects of coronary artery development. Anderson and colleagues ${ }^{1}$ use their expertise in cardiac embryology to synthesize these data, present a comprehensive hypothesized pathway for coronary artery development, and postulate how errors in this pathway may result in clinically observed coronary artery defects.

The authors first give an overview of the origins of coronary artery endothelium and then turn their attention to focus primarily on a thorough description of how coronary arteries develop through both angiogenesis and vasculogenesis. Initially, 3 of the 4 main components of coronary arteries-coronary stems, outflow tract/peritruncal plexus, and epicardial vessels-form independently. Then, the 2 proximal-most connections form with the peritruncal plexus growing to join the coronary stems and the epicardial vessels growing into the aortic root to join the peritruncal plexus. The authors acknowledge that development of the intramural arterial plexus is contested. Finally, the epicardial vessels join the intramural arterial plexus. After establishing this hypothetical pathway, the authors go on to

\footnotetext{
From the ${ }^{\mathrm{a}}$ Department of Surgery, and ${ }^{\mathrm{b}}$ Duke Congenital Heart Research \& Training Laboratory, Duke University, Durham, NC; and 'Duke Children's Pediatric \& Congenital Heart Center, Duke Children's Hospital, Durham, NC.

Disclosures: The authors reported no conflicts of interest.

The Journal policy requires editors and reviewers to disclose conflicts of interest and to decline handling or reviewing manuscripts for which they may have a conflict of interest. The editors and reviewers of this article have no conflicts of interest.

Received for publication Aug 9, 2021; revisions received Aug 9, 2021; accepted for publication Aug 10, 2021; available ahead of print Aug 14, 2021.

Address for reprints: Joseph W. Turek, MD, PhD, MBA, Division of Cardiovascular and Thoracic Surgery, Duke University Medical Center, 2301 Erwin Rd, DUMC 3474, Durham, NC 27710 (E-mail: joseph.turek@ duke.edu).

J Thorac Cardiovasc Surg 2022;164:350-1

$0022-5223 / \$ 36.00$

Copyright (c) 2021 by The American Association for Thoracic Surgery

https://doi.org/10.1016/j.jtcvs.2021.08.026
}

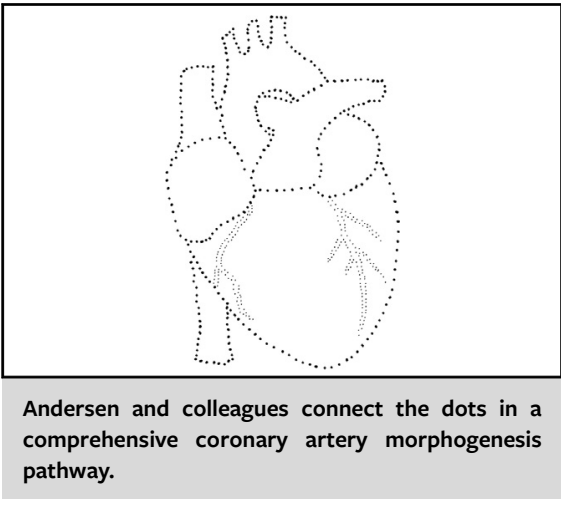

CENTRAL MESSAGE

Coronary arteries develop via

both vasculogenesis and angio-

genesis. Understanding the er-

rors in this pathway that result in

coronary artery defects informs

surgical repair of related cardiac

defects.

correlate existing clinical coronary artery defects with specific pathway errors.

Although the proposed coronary artery developmental pathway is based largely on an extensive review of the literature, the main limitation is that there are some portions that are presented based on educated speculation without prior data as corroborating evidence. For instance, there does not yet exist evidence of how the epicardial vessels establish connections with the intramural arterial plexus. While this is a limitation of the review, the authors openly state that continuing investigation should be undertaken to interrogate the hypothetical steps they present.

Although not the first review of coronary artery development, this review separates itself from the rest of the pack by going beyond regurgitation of previously published work. Instead, the pathway presented by the authors is a reflection not only of a comprehensive reading of the existing literature but also of their fundamental understanding of cardiac embryology. Should further studies support the steps within the pathway introduced by the authors, it would represent an advance in the field of cardiac embryology with an enhanced understanding of clinical congenital cardiac defects. For example, understanding that the proximal development of coronary arteries involves 2 connections-the one between the coronary 
stems and the circumferential peritruncal plexus, as well as the one between the circumferential peritruncal plexus and the epicardial vessels-allows for better understanding of the deviations of coronary patterns seen in anomalous aortic origin of a coronary artery ${ }^{2}$ or in transposition of the great arteries. ${ }^{3}$ Overall, the authors fulfill their promise to lay out a unifying a novel pathway for coronary artery development.

\section{References}

1. Anderson RH, Turner JE, Henderson DJ. The morphogenesis of abnormal coronary arteries in the congenitally malformed heart. J Thorac Cardiovasc Surg. 2022;164:344-9.

2. Turner II, Turek JW, Jaggers J, Herlong JR, Lawson DS, Lodge AJ. Anomalous aortic origin of a coronary artery: preoperative diagnosis and surgical planning. World J Pediatr Congenit Heart Surg. 2011;2:340-5.

3. van Son JA. Classification of origin and proximal epicardial course of coronary arteries in transposition of the great arteries. J Cardiovasc Surg (Torino). 1996;37: $251-4$.
See Article page 344

\section{Commentary: How does that happen, doc?}

\author{
Ravi Vamsee, MBBS, ${ }^{a}$ and Robert D. B. Jaquiss, MD $^{\mathrm{b}}$
}

It is likely that most congenital heart surgeons and pediatric cardiologists have a working knowledge of normal and abnormal cardiac development, with particular focus on "macroscopic" processes such as looping, spiraling, and septation. It is much less likely that practitioners are conversant with the "microscopic" processes involved in the development of the coronary arterial system. This is unfortunate, given the wide spectrum of abnormal coronary anatomy encountered in contemporary practice of pediatric cardiology and congenital heart surgery. Thus, the excellent review by Anderson and colleagues ${ }^{1}$ of contemporary understanding of coronary artery development is most welcome.

Based predominantly on observations from human and murine histology, the authors describe what they term a "mosaic" of developmental processes and tissue origins. Readers will learn that formerly competing hypotheses of

\footnotetext{
From the ${ }^{\mathrm{a}}$ Division of Pediatric Cardiology, Department of Pediatrics, and ${ }^{\mathrm{b}}$ Section of Pediatric and Congenital Cardiac Surgery, Department of Cardiovascular and Thoracic Surgery, University of Texas Southwestern Medical Center, Children's Medical Center, Dallas, Tex.

Disclosures: The authors reported no conflicts of interest.

The Journal policy requires editors and reviewers to disclose conflicts of interest and to decline handling or reviewing manuscripts for which they may have a conflict of interest. The editors and reviewers of this article have no conflicts of interest.

Received for publication Aug 20, 2021; revisions received Aug 20, 2021; accepted for publication Aug 23, 2021; available ahead of print Aug 26, 2021.

Address for reprints: Robert D. B. Jaquiss, MD, Section of Pediatric and Congenital Cardiac Surgery, Department of Cardiovascular and Thoracic Surgery, University of Texas Southwestern Medical Center, Children's Medical Center, 1935 Medical District Dr, Dallas, TX 75235 (E-mail: Robert.jaquiss@utsouthwestern.edu).

J Thorac Cardiovasc Surg 2022;164:351-2

$0022-5223 / \$ 36.00$

Copyright (c) 2021 by The American Association for Thoracic Surgery

https://doi.org/10.1016/j.jtcvs.2021.08.050
}

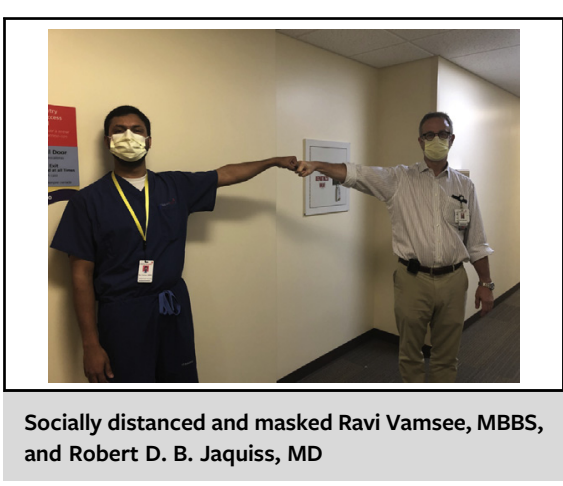

CENTRAL MESSAGE

The understanding of coronary artery development has increased remarkably in the past century, but there remains much to learn.

angiogenesis and vasculogenesis may in fact be complementary, with each explaining development in a different segment of the coronary arterial tree. The process of "reprogramming," whereby venous endothelium is transformed into arterial endothelium, is also introduced. The varied origins of the component of the mature coronary arteries-endothelial stems from the aortic wall, a crown-like plexus of endothelial channels surrounding the developing aortic root, the protoepicardial origin of epicardial coronaries, and ventricular endocardium - are described. The authors then use these developmental concepts to explain a variety of malformations ranging from anomalous origin of the left coronary artery from the pulmonary artery to the bizarre coronary patterns that often accompany pulmonary atresia with intact 